\title{
Metagenomics insight into microbial dynamics in field-scale remediation of crude oil-polluted soil
}

Chioma Blaise Chikere ( $\nabla$ chioma.chikere@uniport.edu.ng )

University of Port Harcourt https://orcid.org/0000-0003-3004-9780

Memory Tekere

University of South Africa

Rasheed Adeleke

North West University

Research article

Keywords: Landfarming, hydrocarbon-biodegradation, field-scale bioremediation, soil microbiome.

Posted Date: May 7th, 2020

DOI: https://doi.org/10.21203/rs.3.rs-26142/v1

License: (c) (1) This work is licensed under a Creative Commons Attribution 4.0 International License.

Read Full License 


\section{Abstract}

Background: The frequency of crude oil pollution has been on the increase following increased exploration, exploitation and production of energy from fossil fuel. Bioremediation has been shown to be eco-friendly and cost-effective method of oil spill remediation. In the Niger Delta, Landfarming has been the most used technique. The aim of this research was to employ metagenomic techniques to understand microbial dynamics during field-scale remediation in the Niger Delta in order to improve and reduce the time of remediation.

Results: The surface $(0.0-0.5 \mathrm{~m})$ sample had an extractable TPH value of $6231 \mathrm{mg} / \mathrm{kg}$. The subsurface samples from $1 \mathrm{~m}, 1.5 \mathrm{~m}$ and $2.0 \mathrm{~m}$ depths had extractable TPH concentration of $4836 \mathrm{mg} / \mathrm{kg}, 9112$ $\mathrm{mg} / \mathrm{kg}$ and $7273 \mathrm{mk} / \mathrm{kg}$ respectively. Proteobacteria dominated the bacterial community of the oilpolluted soil and comprised mainly of the classes Alphaproteobacteria, Betaproteobacteria and Gammaproteobacteria. Alpha diversity analysis revealed the presence of crude oil in the soil reduced microbial diversity. Principal coordinate analysis showed the microbial structure continually changed following changes in the chemical composition of the soil. Mycobacterium, Burkholderia, Methylobacterium and Bacillus were among the core OTUs detected during the period of remediation. Significant variation in pathway abundance particularly pathways for propanoate degradation, benzoate degradation, naphthalene degradation, fatty acid metabolism, polycyclic aromatic hydrocarbon degradation and degradation of xenobiotics were observed when the unpolluted soil was compared to the samples obtained during remediation.

Conclusions: The findings from this study will greatly advance an already preferred landfarming oil spill recovery technique in the Niger Delta.

\section{Introduction}

The anthropogenic release of pollutants particularly crude oil into the environment remains a major environmental challenge. The increasing demand for petroleum products worldwide has led to increased exploration and production with an attendant adverse effect on the environment. Crude oil is a complex mixture of hydrocarbons and other chemical compounds that are considered persistent and toxic to the environment [1]. The release of crude oil into the environment can be during exploration, production, transportation and processing into usable products [1]. Equipment failure, human error and sabotage are mostly responsible for crude oil spills. Some of the major spills include the Amoco Cadiz spillage [2], the Exxon Valdez Spillage [3] and more recently, the Deep water horizon oil spill [4], the Texas city " $Y$ " spill [5] and the Chennai oil-spill in India [6]. In the Niger Delta region of Nigeria where oil exploration began in the 1950s, the impact of oil activities on the environment has been a sad tale with clear evidence of colossal loss of agricultural land, aquaculture and biodiversity $[7,8]$.

The natural ability of microorganisms to degrade hydrocarbons has been demonstrated to be cost effective and environmentally friendly. Approaches to bioremediation include biostimulation and 
bioaugumentation. Biostimulation involves the optimization of environmental and physicochemical factors in such a way that it favours the proliferation of hydrocarbon degrading microorganisms and thus the removal rate of the oil contaminant [1]. On the other hand, bioaugumention is the introduction of established hydrocarbon degrading microorganisms to the polluted environment with the aim of improving the rate of degradation [9]. One very viable technique that explores biostimulation is landfarming. A recent study investigated this approach using oil-polluted soil obtained from the Niger Delta and observed significant reduction in the hydrocarbon content after 110 days [10]. Landfarming involves the enhancement of several environmental and chemical parameters to optimise the activities of indigenous hydrocarbon degrading microorganisms. During landfarming, hydrocarbons are lost through biodegradation and volatilization and the process involves regular tilling, dilution of the hydrocarbon pollutant using less contaminated soil and the addition of fertilizers, enzymes and biosurfactants [1]. Manipulating parameters such as nutrients, $\mathrm{pH}$, moisture and oxygen has been demonstrated to reduce the half-life of hydrocarbon removal from contaminated soils [11-13]. It has been severally applied both in the Niger Delta and other parts of the world $[12,14,15]$. In the Niger Delta, the use of landfarming is particularly advantageous because it requires less machinery, the technology can be easily transferred to the local indigenous people, the impact on the environment is less detrimental, it has been found to be very effective in the Niger Delta in reducing the deleterious effect of oil spills and lastly it creates employment opportunities for the locals in the Niger Delta [12].

The advent of high throughput sequencing platforms and major advances in bioinformatics has revolutionised microbial ecology and brought to the fore microbial responses to the presence of pollutants. Since landfarming is an established approach for hydrocarbon remediation in the Niger Delta, understanding the microbial response to landfarming is important in order to further improve the process. It is also important for predicting future microbial and chemical responses during landfarming of oilpolluted soils in the tropical rainforest zone [16-19]. This study is the first in situ study in the Niger Delta detailing the response of bacterial communities prior to land farming, during-landfarming and postlandfarming of an oil-polluted soil using high-throughput bacterial sequencing techniques. The study also investigated the functional attributes of the bacterial community throughout the entire period of landfarming using a predictive approach. Understanding these events during in situ field-scale landfarming is vital for predicting bacterial community responses to the presence of hydrocarbons in the Niger Delta and also in optimizing the process of landfarming as a green technology for the recovery other petroleum-impacted sites.

\section{Results}

\section{Physicochemical analysis}

The soil samples obtained for characterization of the spill site showed the concentrations of total petroleum hydrocarbons (TPH) and polycyclic aromatic hydrocarbons (PAHs) at different depths of the soil analyzed. The surface (0.0-0.5) sample had an extractable TPH value of $6231 \mathrm{mg} / \mathrm{kg}$. The subsurface samples from $1 \mathrm{~m}, 1.5 \mathrm{~m}$ and $2.0 \mathrm{~m}$ depths had extractable TPH concentration of 
$4836 \mathrm{mg} / \mathrm{kg}, 9112 \mathrm{mg} / \mathrm{kg}$ and $7273 \mathrm{mg} / \mathrm{kg}$ respectively. Values of physicochemical characteristics determined for $\mathrm{pH}$, arsenic, barium, cadmium, cobalt, copper, lead, mercury, nickel, total chromium and zinc are shown in Table 1 together with the Regulator's (DPR's) intervention values.

The concentration of polycyclic aromatic hydrocarbons was low and only detected in the surface sample and the $1 \mathrm{~m}$ depth samples. The surface sample had a PAH concentration of $0.13 \mathrm{mg} / \mathrm{kg}$ while the subsurface sample had PAH concentration of $1.36 \mathrm{mg} / \mathrm{kg}$. The unpolluted soil TPH was $479.7 \mathrm{mg} / \mathrm{kg}$ while TPH concentrations for days 0, 09, 18, 36 and 56 were $8635.68 \mathrm{mg} / \mathrm{kg}, 6125.7 \mathrm{mg} / \mathrm{kg}$, $4171.9 \mathrm{mg} / \mathrm{kg}, 2435.2 \mathrm{mg} / \mathrm{kg}$ and $677.2 \mathrm{mg} / \mathrm{kg}$ respectively.

Table 1

Physicochemical analysis of the oil pollutes soil prior to remediation

\begin{tabular}{|c|c|c|c|c|c|}
\hline Parameter & $0-0.5 \mathrm{~m}$ & $1.0 \mathrm{~m}$ & $1.5 \mathrm{~m}$ & $2.0 \mathrm{~m}$ & DPR Intervention Value \\
\hline ETPH $(\mathrm{mg} / \mathrm{kg})$ & 6231 & 4836 & 9112 & 7273 & 5000 \\
\hline $\mathrm{pH}$ & 6.92 & - & 6.56 & - & - \\
\hline Arsenic $(\mathrm{mg} / \mathrm{kg})$ & 11.8 & - & 10.8 & - & 55 \\
\hline Barium (mg/kg) & 204 & - & 129 & - & 625 \\
\hline Cadmium (mg/kg) & $<2.00$ & - & $<2.00$ & - & 12 \\
\hline Cobalt (mg/kg) & 16.4 & - & 28.8 & - & 240 \\
\hline Copper (mg/kg) & 20.1 & - & 16.3 & - & 190 \\
\hline Lead (mg/kg) & 22.4 & - & 14.8 & - & 530 \\
\hline Mercury $(\mathrm{mg} / \mathrm{kg})$ & $<1.0$ & - & $<1.0$ & - & 10 \\
\hline Nickel (mg/kg) & 35.5 & - & 36.2 & - & 210 \\
\hline Total Chromium $(\mathrm{mg} / \mathrm{kg})$ & 172 & - & 61.3 & - & 380 \\
\hline Zinc (mg/kg) & 60.4 & - & 89.1 & - & 720 \\
\hline
\end{tabular}

\section{Diversity Analysis Following Oil Spill And During Remediation}

Analysis of the effect of the oil spill on microbial diversity revealed the presence of hydrocarbons reduced microbial diversity. Effect of hydrocarbons on bacterial diversity was inferred using Chao1 diversity index. Analysis based on bacterial richness (chao1) revealed the oil-polluted soil prior to any form of remediation had the least bacterial abundance. However, based on Shannon's diversity index, it was found that the least diverse sample was the sample obtained on day 56 . Diversity generally improved 
from day- 0 to day-36 of remediation and only reduced on day 56 when hydrocarbon concentration dropped from 6231 to $677.2 \mathrm{mg} / \mathrm{kg}$ (Fig. 1A). Also, the hydrocarbon concentration in the soil significantly reduced bacterial diversity compared to the pristine soil which represents the soil true diversity prior to the oil spill (Fig. 1B). Following the commencement of intervention by Landfarming, the diversity continued changing and increasing as the concentration of hydrocarbons in the soil reduced. Principal coordinates analysis ( $\mathrm{PCoA}$ ) revealed the samples clustered separately within the ordination space, and suggest how the bacterial community changes as different hydrocarbon fractions were degraded (Fig. 2).

* [PERMANOVA] F-value: 1.0506; R-squared: 0.34438; p-value <0.3

\section{Microbial Dynamics And Abundance During Remediation}

A total 1,211 bacterial species were detected for all the samples. The bacterial metagenome for all the samples was dominated by Proteobacteria for the oil polluted and Acidobacteria for the unpolluted soils (Fig. 3) with an average abundance of $64 \%$. It was observed that the abundance of proteobacteria increased from the start of remediation ( $68 \%$ on day- 0 ) to $70 \%$ on day- 9 before declining to $55 \%$ on day18 and $30 \%$ on day-36. Pre-remediation, the dominant phyla were Proteobacteria (46\%) and Actinobacteria (43\%) while in the unpolluted soil Acidobacteria and Actinobacteria made up $40 \%$ and $18 \%$ of the soil microbiome respectively. At the class level, the dominant bacterial classes with at least $1 \%$ abundance in at least 1 sample are presented in Fig. 3B. Alphaproteobacteria pre-remediation was $26 \%$ but increased to $28 \%$ and $37 \%$ on days $0-9$ before significantly declining to $16 \%$ and $9 \%$ on days 18 and 36 respectively. This finding was similar for Betaproteobacteria but different for Gammaproteobacteria which recorded significant improvement between days 18-36. Baseline Betaproteobacteria abundance was $16 \%$ but reduced to $8 \%$ on day 36 while Gammaproteobacterial abundance improved from $1 \%$ on commencement of remediation to $22 \%$ on day- 18 of the site remediation. As the dominance of Proteobacteria increased during the early stages of remediation, there was also a simultaneous decrease in the abundance of Actinobacteria throughout the period of remediation. Actinobacteria reduced from $43 \%$ prior to intervention by Landfarming to $4 \%$ on day- 56 .

Investigation of the polluted soil microbiome at the family level revealed important differences between the oil-polluted and unpolluted soils. For instance, at all sampling days during remediation (apart from Day 18) Burkholderiaceae and Mycobacteriaceae were the dominant bacterial family while the unpolluted soil had Solibacteriaceae (19\%) and Chthoniobacteraceae (17\%) as the most abundant bacterial families (Fig. 4A). Unlike on day-0 where Burkholderiaceae (40\%) and Mycobacteriaceae (17\%) were the dominant bacterial families, on day 56 , the most abundant bacterial families were Burkholderiaceae (31\%) and Bacillaceae (27\%). The core bacterial families in the site pre-remediation and during remediation with at least $20 \%$ prevalence and $5 \%$ relative abundance were detected to be Burkholderiaceae, Bacillaceae, Mycobacteriaceae, Bradyrhizobiaceae, Chthoniobacteraceae, Solibacteriaceae, Acidobacteriaceae, Caulobacteraceae and Methylobacteriaceae. 
At the genus level, it was observed that the early stages (day-0 and day-9) of remediation were particularly dominated by Burkholderia unlike in the baseline oil-polluted soil where mycobacterium dominated. Major differences were however observed between days 18 and 36 (Fig. 4B). The core bacterial genera detected in the samples obtained during this period of remediation included Mycobacterium, Burkholderia, Bacillus, Sphingomonas, Candidatus Xiphinematobacter, Pseudomonas and Candidatus Solibacter. Comparison of the crude oil polluted soils during remediation to that of the unpolluted soil revealed Candidatus Xiphinematobacter was a common feature that dominated the community structure in the unpolluted soil and in the later stages of remediation (days 36-56).

\section{Predictive Microbial Community Functional Response During Remediation}

To determine the functional responses of the bacterial community to the environmental stress caused by the presence of the crude oil spill, the GREENGENES classified bacterial species were subjected to further analysis using PICRUST. $₫ 6,909$ KEGG orthologs were detected for the entire samples. The mean abundance of pathways detected was $427,917.46$. The oil polluted samples were all compared to the pristine soil for differentially represented KEGG pathways. Thirty-five pathways were found to be differentially represented between the pristine soil the polluted soil prior to Landfarming. The pathways were mainly pathways for hydrocarbons degradation and they include naphthalene degradation, polycyclic aromatic hydrocarbon degradation, benzoate and aminobenzoate degradation pathways among others (Fig. 5A - 5C). As remediation commenced mostly the same predicted pathways remained significantly differentially represented from day zero to day 18 after which a decline in the degradative pathways was observed. On days 36 and 56 only pathway for transporters and pathways for phosphonate and phosphinate metabolism were differentially represented.

* PSBBB = Polluted soil prior to landfarming

*PSB0 $=$ Day 0

* UUS = Unpolluted soil

* PSB9 = Day 09

* PSB18 = Day 18

* PSD56 = Day 56

* PSD36 = Day 36

Also, from the 16S rRNA metagenomes, proteins numbering 5649 were predicted and classified as KEGG orthologs (KOs) across all the samples. Several genes associated with the degradation of polycyclic aromatic hydrocarbons (PAHs), naphthalene, benzoate, toluene, chloroalkane/chloroalkene and 
chlorohexane/chlorobenzene degradation were found to be differentially abundant across all the samples obtained before remediation, during remediation and in the unpolluted soil as presented in Fig. 6.

It was observed that the genes responsible for hydrocarbon degradation were present in both the oilpolluted and unpolluted soils. However, for all the hydrocarbon degradation pathways analysed, genes for hydrocarbon degradation was more enriched in the oil-polluted soils compared to the unpolluted soil. Also, in most cases, a high enrichment of the genes was observed in the baseline oil-polluted soil and progressively reduced as remediation progressed. For example, K01692 associated with the degradation of benzoate was $33 \%$ in the unpolluted soil, $44 \%$ in the baseline sample, $40 \%$ on day- $-40 \%$ on day- $9,39 \%$ on day-18, 33\% on day-36, and $34 \%$ on day-56 (Fig. 6C). Also, K00121 associated with Naphthalene degradation was observed to be $21 \%$ in the unpolluted soil, $46 \%$ in the oil-polluted soil obtained prior to remediation, $39 \%$ on day- $0,37 \%$ on day- $9,45 \%$ on day $-18,28 \%$ on day- 36 , and $27 \%$ on day- -56 as presented in Fig. 6B). Majority of the classified KOs were observed to have followed this trend in most of the investigated proteins responsible for hydrocarbon degradation.

Bacterial contribution to the overall functional metagenome revealed that, in the oil-polluted soil samples, Mycobacterium (78\%), Bradyrhizobium (8\%), Phenylobacterium (4.2\%) and Burkholderia (3\%) contributed the most to the KEGG ortholog K01692 (enoyl-CoA hydratase); associated with the degradation of benzoate, aminobenzoate and caprolactam. The same group of bacterial genera were also the main contributors to KEGG ortholog K00121 (S-(hydroxymethyl) glutathione dehydrogenase/alcohol dehydrogenase) associated with chloroalkane and naphthalene. Bradyrhizobium, Burkholderia and Methylobactrium were the key contributors (> 1\%) in the oil-polluted soil sample to K00480 (salicylate hydroxylase; associated with both dioxin and naphthalene degradation) and K01856 (muconate cycloisomerase; associated with Chlorocyclohexane, florobenzoate, benzoate and toluene degradation).

\section{Discussion}

This study provides an insight on microbial diversity and dynamics during field scale Landfarming of an oil polluted site in the Niger Delta of Nigeria. Landfarming has been the preferred and most used remediation technique for the recovery of oil polluted sites in the Niger Delta. The essence of this study was to provide details on the impact of the intermittent oil discharge in the environment on bacterial diversity and to determine their responses and how it could be exploited to enhanced recovery of the oil polluted sites. Chemical and microbiological properties of the polluted soil were monitored throughout the period of Landfarming to make useful conclusions that will improve the environmental recovery of crude oil polluted soils in the Niger Delta and beyond.

Soil chemical analysis for hydrocarbon concentration revealed the polluted soil required intervention as the obtained soil extractable TPH ranged from $4836 \mathrm{mg} / \mathrm{kg}$ to $9112 \mathrm{mg} / \mathrm{kg}$ which is above DPR's intervention limit for oil pollution in Nigeria. The soil extractable PAH was below the intervention limit as poly aromatic hydrocarbons was only detected in very minimal concentration and in just two of the oil 
polluted soil samples. The reason for the low PAH concentration is connected to the properties of the spilled oil as the oil was known to contain a very small fraction of aromatic hydrocarbons. The high TPH prompted the intervention by landfarming and provided an opportunity to gain an in-situ insight into bacterial community structure, dynamics and response during oil spill in the Niger Delta using high through-put sequencing techniques. As remediation progressed, the soil extractable TPH continued to reduce in response to the remedial action undertaken during a 56-day period. It was observed that the highest reduction in TPH was achieved within the first 36 days of remediation which is typical of soil undergoing bioremediation. A similar observation has been made by several researchers [12, 20]. In this study approximately $72 \%$ of the total extractable TPH was removed within the first 36 days of remediation.

Diversity analysis of both the pristine and oil polluted soils showed the environmental stress posed by the release of crude oil into the environment during the spill greatly impacted bacterial diversity and richness. It has been severally reported that the presence of hydrocarbons in the environment reduces diversity and drives a selection of bacterial species with the capacity to degrade hydrocarbons [21-23]. In all the samples analysed prior to and during remediation, the unpolluted soil samples had the most diversity of bacterial species. The diversity continued to change during remediation as different hydrocarbon fractions were removed. This was most represented in the PCoA plot where the samples obtained during the period of remediation spread across different points indicating a changing microbial structure following the depletion of various fractions of hydrocarbons and an overall reduction in crude oil concentration in the soil. Kim et al. [24] also reported the potential influence the degradation of different hydrocarbon fractions in crude oil polluted soils could have in determining the microbial community structure. Siles and Margesin [25] also studied the influence of reduction in different hydrocarbon fractions during bioremediation on bacterial community dynamics and diversity. Their finding revealed significant changes in microbial structure as remediation progressed.

In this study the phylum Proteobacteria dominated in all the oil-polluted soil samples. Soil samples are known to be mostly dominated by Proteobacteria [26-28], however, in crude oil polluted soils they are known to be even more abundant $[21,29]$. Alphaproteobacteria dominated the early stages of remediation, however as remediation progressed the abundance of gammaproteobacteria significantly increased. In a study of microbial community dynamics during bioremediation, Siles and Margesin [25] revealed that gammaproteobacteria became dominant after 15 weeks of bioremediation while there was a corresponding reduction in the abundance of Alphaproteobacteria, Betaproteobacteria and Deltaproteobacteria. This phenomenon commonly refered to as "gamma-shift" has been frequently reported during bioremediation and in soils with dynamic hydrocarbon concentrations [25, 30, 31]. A number of studies have also reported gammaproteobacteria to be actively involved in hydrocarbon degradation $[25,32,33]$. The loss of approximately $72 \%$ of the ETPH within the period of dominance of gammaproteobacteria is an indication of their role in the degradation of hydrocarbons. This was also confirmed from the results of the predictive functional profile during the period of remediation as the pathways for hydrocarbon degradation significantly increased between days-0 and 18 . 
Mycobacterium, Burkholderia, Rhodoplanes and Bacillus were among the core microbiome detected during this study. All of these organisms have been severally reported to be involved in the degradation of various types of hydrocarbons [28,34-37] including the degradation of alkanes and aromatic fractions of hydrocarbons. Most of the organisms found to be differentially represented in the oil polluted soils have also been severally reported to be potential hydrocarbon degraders and thus their presence in the oil polluted soil could be linked to the role they played in hydrocarbon stressed environment.

Predictive functional profiling of the soil samples revealed several pathways involved in the degradation of various hydrocarbon fractions were significantly abundant in the oil polluted soil prior to remediation and during the early stages of remediation. Naphthalene degradation, polycyclic aromatic hydrocarbon degradation, benzoate and aminobenzoate degradation pathways were among the significantly differential pathways in the oil polluted soils. It was observed that key pathways for hydrocarbon degradation were particularly higher during the early stages of remediation (days $0-18$ ). This stage of remediation also coincided with when the greatest loss of hydrocarbon was recorded. The predicted increase in specific pathways responsible for hydrocarbon degradation could be said to be responsible for the major hydrocarbon loss during the early stages of bioremediation. The reduction in abundance of these degradation pathways during the later stages of Landfarming and a subsequent resurgence of Alphaproteobacteria (day-56) is also a confirmation of the important role these pathways play during bioremediation. Several studies have employed the use of predictive methods to profile crude oil polluted soils and several other environments [38-41]. Using predictive functional profiling, Bao et al. [38] was able to reveal that majority of differentially detected functional genes responsible for both saturates and aromatic hydrocarbon degradation in their study were associated with oil polluted soils. Bell et al. [16] in another study observed a 4 to $4.5 \%$ increase in genes responsible for Xenobiotics Biodegradation and Metabolism in crude oil amended treatments during a remediation experimentation.

In this study, the overall metacommunity activities with particular reference to hydrocarbon degrading genes revealed Burkholderia, Mycobacterium, Methylobacterium, Phenylobacterium and Bradyrhizobium which were among the core bacterial genera were part of the main contributors to the metacommunity functions. This finding suggests that the core microbiome detected proliferated as a result of the hydrocarbon pollutant in the soil.

\section{Conclusion}

The success of bioremediation is dependent on soil microbiome features such as abundance, functional diversity and the soil microbial structure. Hence the understanding of microbial dynamics during remediation is very important for developing more advanced technique for accelerated biodegradation. This study provides an insight into microbial dynamics during field-scale landfarming of crude oil polluted soils. The findings made can be used to design accelerated engineered landfarming processes for the clean-up of oil spills in the Niger Delta and beyond.

\section{Methodology}




\section{Sampling and site description}

The spill site where this study was conducted is located in Ibaa Community in Emohua Local Government Area in Rivers State, Nigeria (GPS coordinates E 6.804116; N 4.969581). The spill was first reported on the 8th of May, 2016 and it was as a result of an operational error on a Manifold operated by a multinational oil Company. An estimated $304 \mathrm{bbl}$ of crude oil was released into the surrounding environment prompting remediation using the Landfarming technique.

Samples were collected from $0.0-0.5 \mathrm{~cm}, 1 \mathrm{~m}, 1.5 \mathrm{~m}$ and $2 \mathrm{~m}$ depths for both metagenomic and physicochemical analysis following the spill. Samples were collected using soil auger and transferred in sterile containers to the laboratory for analysis. As remediation of the spill site commenced, samples were collected on days $0,9,18,36$ and 56 to monitor reduction in pollutants concentrations and the role of the indigenous microbiome to the changing soil chemistry as well as the bacterial responses to the spill.

\section{Physicochemical Analyses}

The residual TPH and PAHs were extracted from the soil samples and quantified using gas chromatograph - flame ionization detector (GC-FID) and Gas chromatograph - Mass spectrophotometer (GC-MS), (an Agilent 6890GC, Agilent technologies, Wilmington, USA GC equipped with 5975B MSD and MSD Chemstation version D. 03.00), according to the methods of USEPA 8270 and USEPA 8015, respectively. The carrier gas was helium and the column with catalogue number HP-5(19091 J-413). Physicochemical parameters such as $\mathrm{pH}$, nitrate, moisture content, phosphate, potassium, electrical conductivity, total organic carbon, zinc, nickel and lead were determined according to methods of APHA 4500 and ASTM D1691, respectively.

\section{Genomic Dna Extraction And Sequencing}

Microbial composition and structure were determined by the extraction and analysis of total genomic DNA and sequencing of 16S rRNA genes (Bacteria and Archaea) from both the hydrocarbons polluted and unpolluted soils. The DNA was extracted from soil samples with a Zymo Research DNA extraction kit (Zymo Research CA, USA). The primer pairs 27F (51AGAGTTTGATCMTGGCTCAG-31) and 1492R (51GGGTTACCTTGTTACGACTT31) were used for PCR based 16S rRNA gene amplification and sequencing on an Illumina MiSeq platform (Illumina Inc. CA, USA). Sequencing was conducted using v3 chemistry (paired-end 300 bp reads) according to standard protocols.

\section{Sequence Processing And Analysis}


Illumina MiSeq sequences were processed using QIIME v2018.6[42]. Demultiplexed fastq reads was imported into QIIME using the CASAVA 1.8 format for paired-end sequences. Chimeric sequences, marginal sequence errors and noisy sequences were filtered using DADA2 [43]. Dereplicated sequences were further clustered into operational taxonomic units using the GREENGENES database at $97 \%$ similarity while employing the VSEARCH open reference OTU picking technique [44]. The clustered sequences were assigned taxonomy using q2-feature-classifier plugin [45] and the Naïve Bayes classifier that was trained on the Greengenes (May 2013 release) 99\% OTUs. Alpha and Beta diversity analysis was performed in $\mathrm{R}$ using the Phyloseq package [46]. Alpha diversity was calculated by Shannon's diversity index, observed OTUs, Chao1, and Simpson diversity index. Principal coordinate analyses (PCoA) were performed based on Bray-Curtis distance and determination of statistically significant difference in diversity was performed using Permutational multivariate analysis of variance (PERMANOVA). Exploration of the core bacterial taxa's in the oil polluted soils as remediation progressed, the determination of differentially abundant bacterial taxa's and the detection of the dynamics of the bacterial community structure was all achieved using the MicrobiomeAnalyst [47].

\section{Declarations}

\section{Ethics approval and consent to participate}

Not applicable

\section{Consent for publication}

Not applicable

\section{Availability of data and materials}

Datasets generated/analyzed during this study are available in the GenBank repository under the Bioproject accession number PRJNA592287.

\section{Competing interests}

The authors declare that they have no competing interests

\section{Funding}

The research was conducted with TWAS-UNESCO Associateship Fellowship given to CB Chikere and hosted by Prof. Memory Tekere in University of South Africa (UNISA) following existing mutual agreement with TWAS. No physical funding was given to UNISA for the research by TWAS.

\section{Authors' contributions}

CBC conceived, designed and carried out the work; CBC, MT and RA were involved in data analysis and interpretation of data; $\mathrm{CBC}, \mathrm{MT}$ and RA drafted the manuscript and all three authors approved the 
submitted version.

\section{Acknowledgment}

Authors acknowledge The World Academy of Sciences (TWAS) Trieste, Italy for 2016 TWAS-UNESCO Associateship Fellowship given to CB Chikere hosted by UNISA in Professor Memory Tekere's Research Laboratory.

\section{References}

1. Ortega MF, Guerrero DE, García-Martínez MJ, Bolonio D, Llamas JF, Canoira L, et al. Optimization of Landfarming Amendments Based on Soil Texture and Crude Oil Concentration. Water Air Soil Pollut. 2018;229:229-34.

2. Swannell RP, Lee K, McDonagh M. Field evaluations of marine oil spill bioremediation. Microbiol Rev. 1996;60:342-65.

3. Motta FL, Stoyanov SR, Soares JBP. Application of solidifiers for oil spill containment: A review. Chemosphere. 2018;194:837-46.

4. Crone TJ, Tolstoy M. Magnitude of the 2010 gulf of Mexico oil leak. Science (80- ). 2010;330:634.

5. Bacosa HP, Thyng KM, Plunkett S, Erdner DL, Liu Z. The tarballs on Texas beaches following the 2014 Texas City "Y" Spill: Modeling, chemical, and microbiological studies. Mar Pollut Bull. 2016;109:236-44.

6. Han Y, Nambi IM, Prabhakar CT, Prabhakar Clement T. Environmental impacts of the Chennai oil spill accident - A case study. Sci Total Environ. 2018;626:795-806.

7. UNEP. Environmental Assessment of Ogoniland United Nations Environment Programme. 2011.

8. Pa J, Lindén O, Pålsson J. Oil Contamination in Ogoniland, Niger Delta. Ambio. 2013;42:685-701.

9. Azubuike CC, Chikere CB, Okpokwasili GC. Bioremediation techniques-classification based on site of application: principles, advantages, limitations and prospects. World J Microbiol Biotechnol. 2016;32:180.

10. IUCN-NDP. Sustainable Remediation and Rehabilitation of Biodiversity and Habitats of Oil Spill Sites in the Niger Delta Main Report including Recommendations for the Future. 2013.

11. Chikere $\mathrm{CB}$, Azubuike CC. Catechol-2,3-dioxygenase screening in putative hydrocarbon utilizing bacteria. Int Res J Microbiol. 2012;4:1-6.

12. Brown DM, Okoro S, Gils J Van, Spanning R Van, Bonte M, Hutchings T, et al. Comparison of landfarming amendments to improve bioremediation of petroleum hydrocarbons in Niger Delta soils. Sci Total Environ. 2017;596-597:284-92.

13. Ezenne GI, Nwoke OA, Ezikpe DE, Obalum SE, Ugwuishiwu BO. Use of poultry droppings for remediation of crude-oil-polluted soils: Effects of application rate on total and poly-aromatic hydrocarbon concentrations. Int Biodeterior Biodegrad. 2014;92:57-65. 
14. Atlas RM, Bragg JR. Removal of oil from shorelines: biodegradation and bioremediation. In: Wiens JA, editor. Oil Environ., Cambridge: Cambridge University Press; 2013, p. 176-97.

15. Heitzer A, Sayler GS. Monitoring the efficacy of bioremediation. Trends Biotechnol. 1993;11:334-43.

16. Bell TH, Stefani FOP, Abram K, Champagne J, Yergeau E, Hijri M, et al. A Diverse Soil Microbiome Degrades More Crude Oil than Specialized Bacterial Assemblages Obtained in Culture. Appl Environ Microbiol. 2016;82:5530-41.

17. Chikere CB, Obieze CC, Okerentugba P. Molecular Assessment of Microbial Species Involved in the Biodegradation of Crude Oil in Saline Niger Delta Sediments Using Bioreactors. J Bioremediation Biodegrad. 2015;06:1-7.

18. Guarino C, Spada V, Sciarrillo R. Assessment of three approaches of bioremediation (Natural Attenuation, Landfarming and Bioagumentation - Assistited Landfarming) for a petroleum hydrocarbons contaminated soil. Chemosphere. 2017;170:10-6.

19. Sutton NB, Maphosa F, Morillo JA, Al-Soud AA, Langenhoff, A. A. M. Grotenhuis T, Rinaarts HHM, et al. Impact of long-term diesel contamination on soil microbial community structure. Appl Environ Microbiol. 2013;79:619-30.

20. Grace Liu P-W, Chang TC, Whang L-M, Kao C-H, Pan P-T, Cheng S-S. Bioremediation of petroleum hydrocarbon contaminated soil: Effects of strategies and microbial community shift. Int Biodeterior Biodegradation. 2011;65:1119-27.

21. Saul, D. J., Aislabie, J. M., Brown, C. E., Harris, L. and Foght JM. Hydrocarbon contamination changes the bacterial diversity of soil from around Scott Base, Antarctica. FEMS Microbiol Ecol. 2005;53:14155 .

22. Chikere CB, Obieze CC. Fungal Diversity and Dynamics During Bioremediation of Crude Oilpolluted Soil. Curr Biotechnol. 2017;7:89-97.

23. Huettel M, Overholt WA, Kostka JE, Hagan C, Kaba J, Brian W, et al. Degradation of Deepwater Horizon oil buried in a Florida beach in fl uenced by tidal pumping Gulf of Mexico 2018;126:488500 .

24. Kim J, Lee AH, Chang W. Enhanced bioremediation of nutrient-amended, petroleum hydrocarboncontaminated soils over a cold-climate winter: The rate and extent of hydrocarbon biodegradation and microbial response in a pilot-scale biopile subjected to natural seasonal freeze-thaw $t$. Sci Total Environ. 2018;612:903-13.

25. Siles JA, Margesin R. Insights into microbial communities mediating the bioremediation of hydrocarbon-contaminated soil from an Alpine former military site. Appl Microbiol Biotechnol. 2018;102:4409-21.

26. Fahrenfeld N, Cozzarelli IM, Bailey Z, Pruden A. Insights into Biodegradation Through Depth-Resolved Microbial Community Functional and Structural Profiling of a Crude-Oil Contaminant Plume. Microb Ecol. 2014;68:453-62.

27. Roesch LF, Fulthorpe RR, Riva A, Casella G, Hadwin KM, Daroub SH, et al. Pyrosequencing enumerates and contrasts soil microbial diversity. ISME J. 2007;1:283-350. 
28. Yang $Y$, Wang N, Guo X, Zhang Y, Ye B. Comparative analysis of bacterial community structure in the rhizosphere of maize by highthroughput pyrosequencing. PLoS One. 2017;12:1-11.

29. Zhang D, Margesin R. Characterization of culturable heterotrophic bacteria in hydrocarboncontaminated soil from an alpine former military site. World J Microbiol Biotechnol. 2014;30:171724.

30. Militon C, Boucher D, Vachelard C, Perchet G, Barra V, Troquet J, et al. Bacterial Community changes during bioremediation of aliphatic hydrocarbon-contaminated soil. FEMS Microb Ecol. 2010;74:66981.

31. Dong Y, Lang Z, Kong X, Lu D, Liu Z. Kinetic and multidimensional profiling of accelerated degradation of oil sludge by biostimulation. Environ Sci Process Impacts. 2015;17:763-74.

32. Head IM, Jones DM, Roling WFM. Marine microorganisms make a meal of oil. Nat Rev Microbiol. 2006;4:173-82.

33. Labbe D, Margesin R, Schinner F, Whyte LG, Greer CW. Comparative phylogenetic analysis of microbial communities in pristine and hydrocarbon-contaminated Alpine soils. FEMS Microbiol Ecol. 2007;59:466-75.

34. Cerniglia CE. Recent Advances in the Biodegradation of Polycyclic Aromatic Hydrocarbons by Mycobacterium Species. Util. Bioremediation to Reduce Soil Contam. Probl. Solut., Dordrecht: Springer Netherlands; 2003, p. 51-73.

35. Al-Sharidah A, Richardt A, Golecki JR, Dierstein R, Tadros MH. Isolation and characterization of two hydrocarbon-degrading Bacillus subtilis strains from oil contaminated soil of Kuwait. Microbiol Res. 2000;155:157-64.

36. Das N, Chandran P. Microbial Degradation of Petroleum Hydrocarbon Contaminants: An Overview. Biotechnol Res Int. 2011;2011:1-13.

37. Kim TJ, Lee EY, Kim YJ, Cho K-S, Ryu HW. Degradation of polyaromatic hydrocarbons by Burkholderia cepacia 2A-12. World J Microbiol Biotechnol. 2003;19:411-7.

38. Bao YJ, Xu Z, Li Y, Yao Z, Sun J, Song H. High-throughput metagenomic analysis of petroleumcontaminated soil microbiome reveals the versatility in xenobiotic aromatics metabolism. JES. 2016;56:1-11.

39. Mukherjee AKA, Chettri B, Langpoklakpam JS, Basak P, Prasad A, Mukherjee AKA, et al. Bioinformatic approaches including predictive metagenomic profiling reveal characteristics of bacterial response to petroleum hydrocarbon contamination in diverse environments. Sci Rep. 2017;7:1108:1-22.

40. Hariharan J, Grewal PS, Dick WA, Staton ME. Predictive Functional Profiling of Soil Microbes under Different Tillages and Crop. The Ohio State University, 2015.

41. Mukherjee A, Chettri B, Langpoklakpam J, Basak P, Prasad A, Mukherjee A, et al. Metagenomic Characteristics of Bacterial Response to Petroleum Hydrocarbon Contamination in Diverse Environments as Revealed by Functional Taxonomic Strategies. BioRxiv. 2016:097063.

42. Bolyen E, Rideout JR, Dillon MR, Bokulich NA, Abnet C, Ghalith GA Al, et al. QIIME 2: Reproducible, interactive, scalable, and extensible microbiome data science. PeerJ Prepr. 2018:9-10. 
43. Callahan BJ, McMurdie PJ, Rosen MJ, Han AW, Johnson AJA, Holmes SP. DADA2: High-resolution sample inference from Illumina amplicon data. Nat Methods. 2016;13:581-3.

44. Rognes T, Flouri T, Nichols B, Quince C, Mahé F. VSEARCH: a versatile open source tool for metagenomics. PeerJ. 2016;4:e2584.

45. Bokulich NA, Kaehler BD, Rideout JR, Dillon M, Bolyen E, Knight R, et al. Optimizing taxonomic classification of marker-gene amplicon sequences with QIIME 2's q2-feature-classifier plugin. Microbiome. 2018;6.

46. McMurdie PJ, Holmes S. Phyloseq: an R package for reproducible interactive analysis and graphics of microbiome census data. PLoS One. 2013;8:e61217.

47. Dhariwal A, Chong J, Habib S, King IL, Agellon LB, Xia J. MicrobiomeAnalyst: a web-based tool for comprehensive statistical, visual and meta-analysis of microbiome data. Nucleic Acids Res. 2017;45:W180-8.

48. Langille MGI, Zaneveld J, Caporaso JG, Mcdonald D, Knights D, Reyes JA, et al. Predictive functional profiling of microbial communities using $16 \mathrm{~S}$ rRNA marker gene sequences. Nat Biotechnol. 2013;31:814-21.

49. Benjamini Y, Hochberg Y. Controlling the False Discovery Rate: A Practical and Powerful Approach to Multiple Testing. J R Stat Soc Ser B. 1995;57:289-300.

\section{Figures}
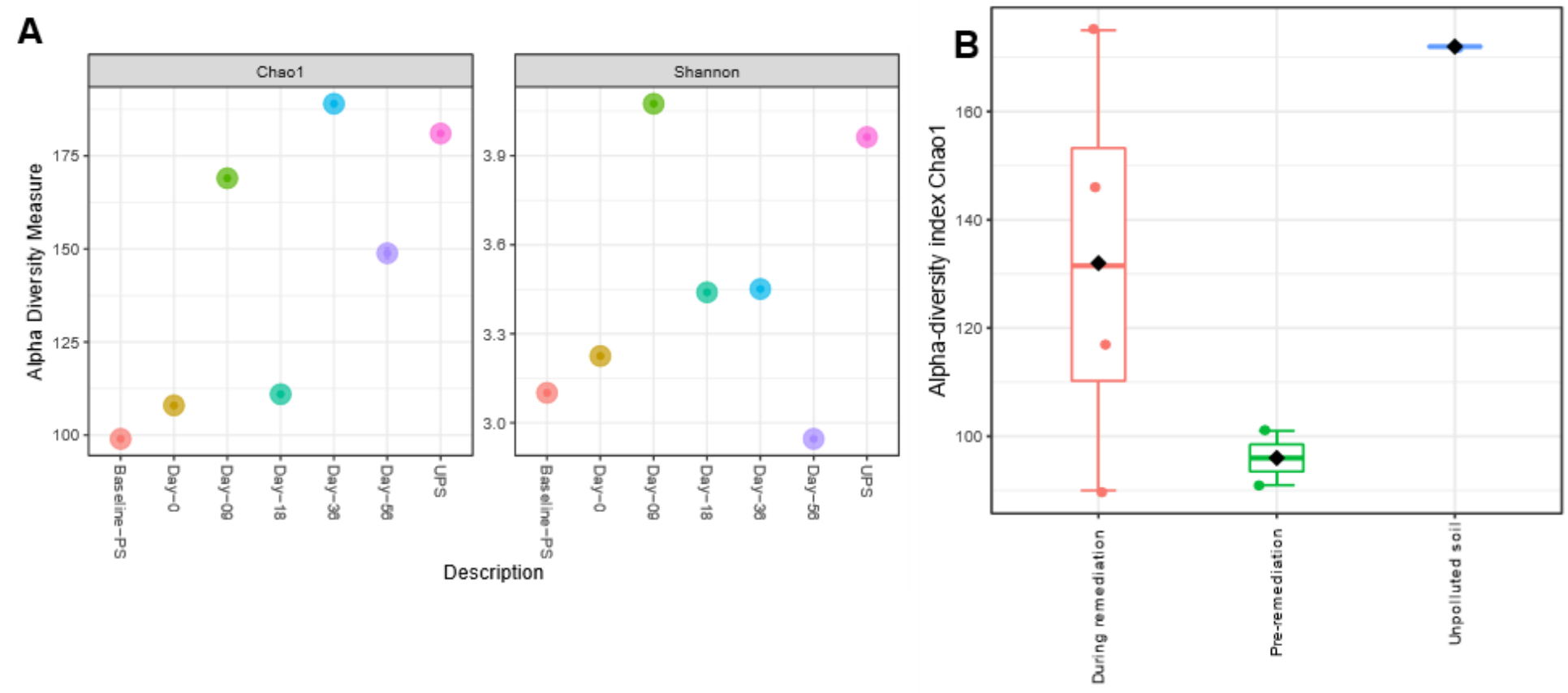

\section{Figure 1}

Impact of hydrocarbon stress on the microbial diversity across all samples (A) and the samples obtained before remediation, during remediation and in the unpolluted soil (B). 


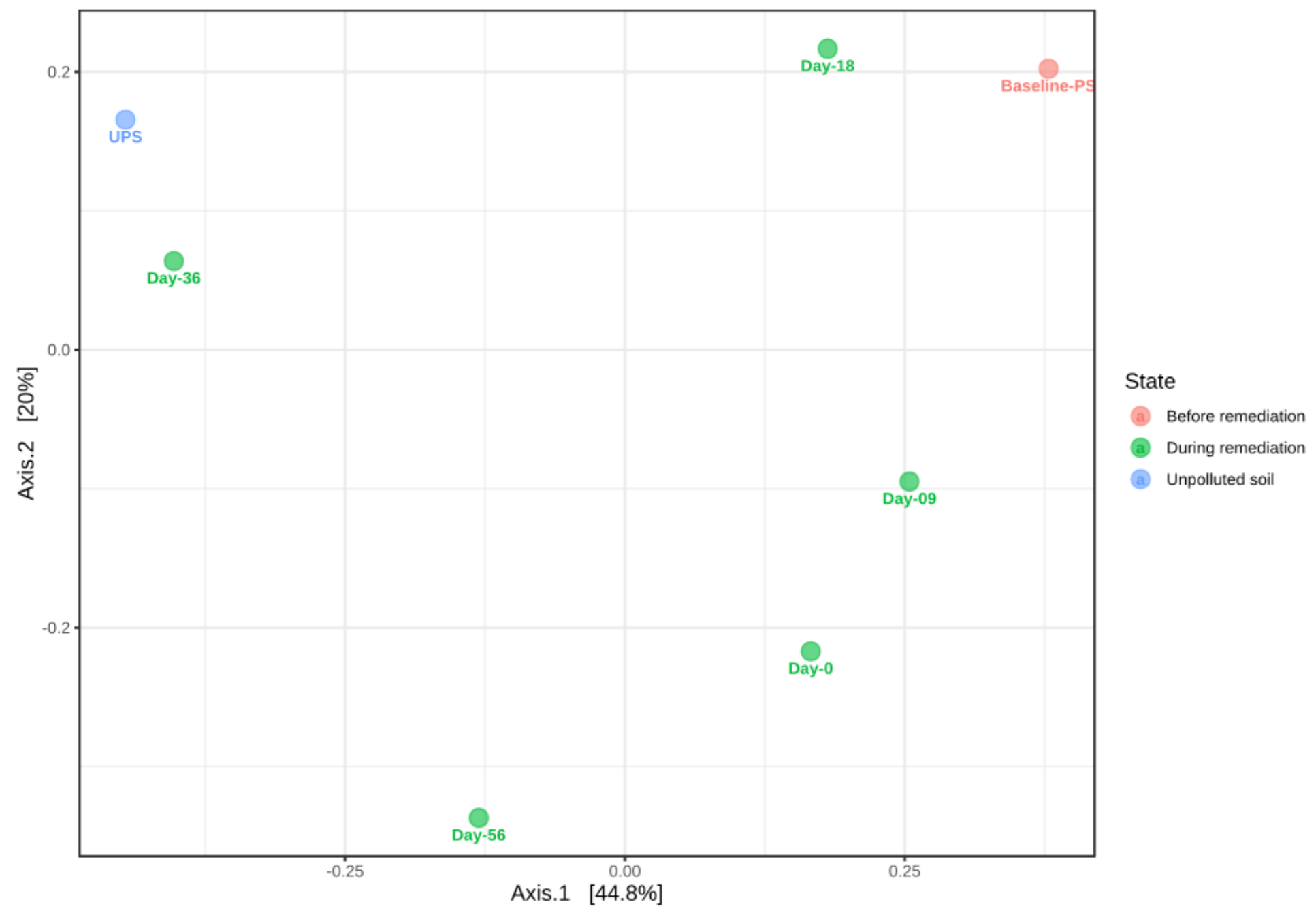

Figure 2

Beta diversity analysis using Bray-cutis distance for all the samples obtained prior to and during remediation. * [PERMANOVA] F-value: 1.0506; R-squared: 0.34438; $p$-value $<0.3$ 

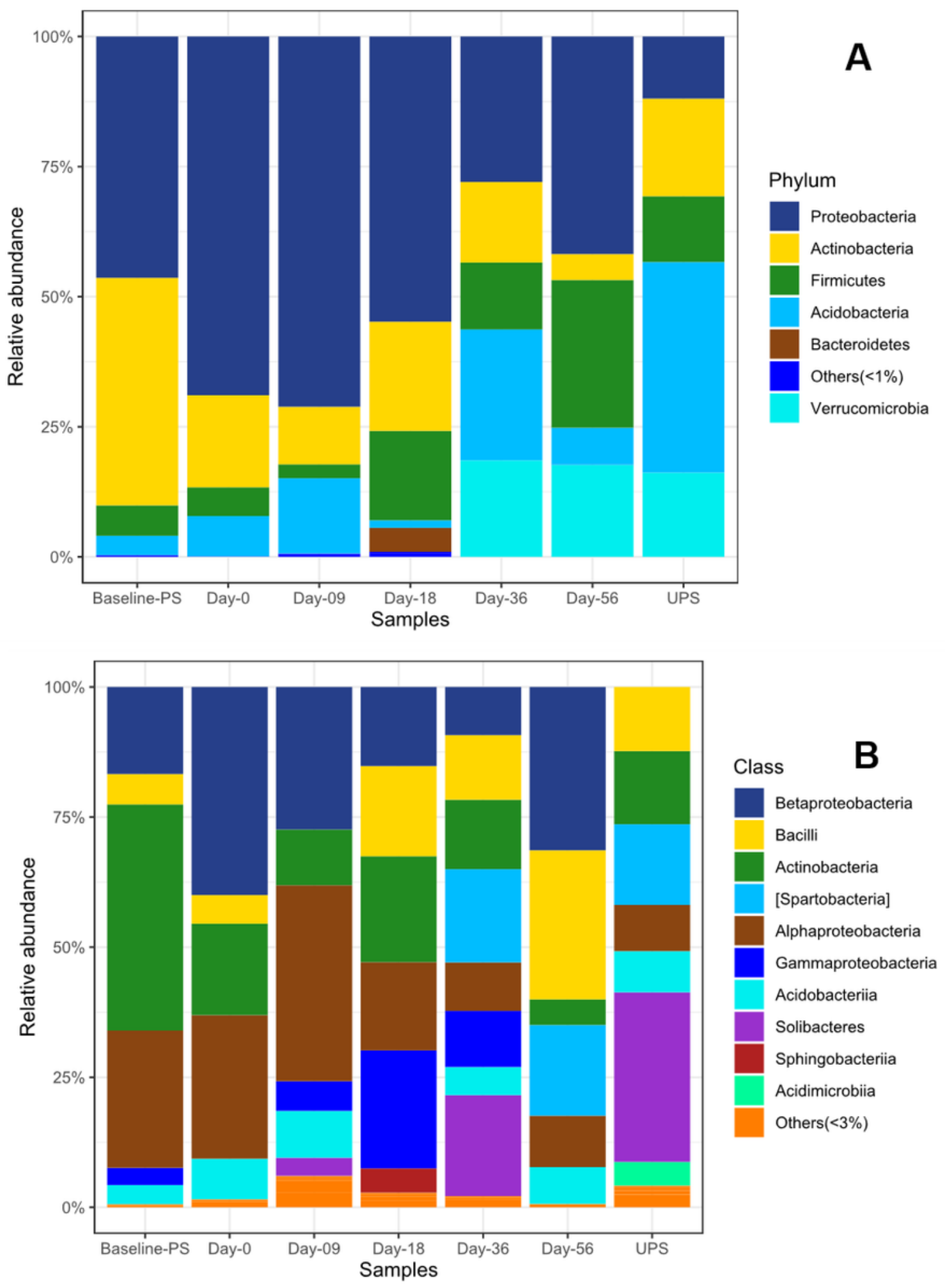

\section{Figure 3}

Representation of bacterial abundance across the samples (pristine soil, polluted soils and soils analysed during landfarming) at the phylum level (A) and class (B) taxonomic levels. 

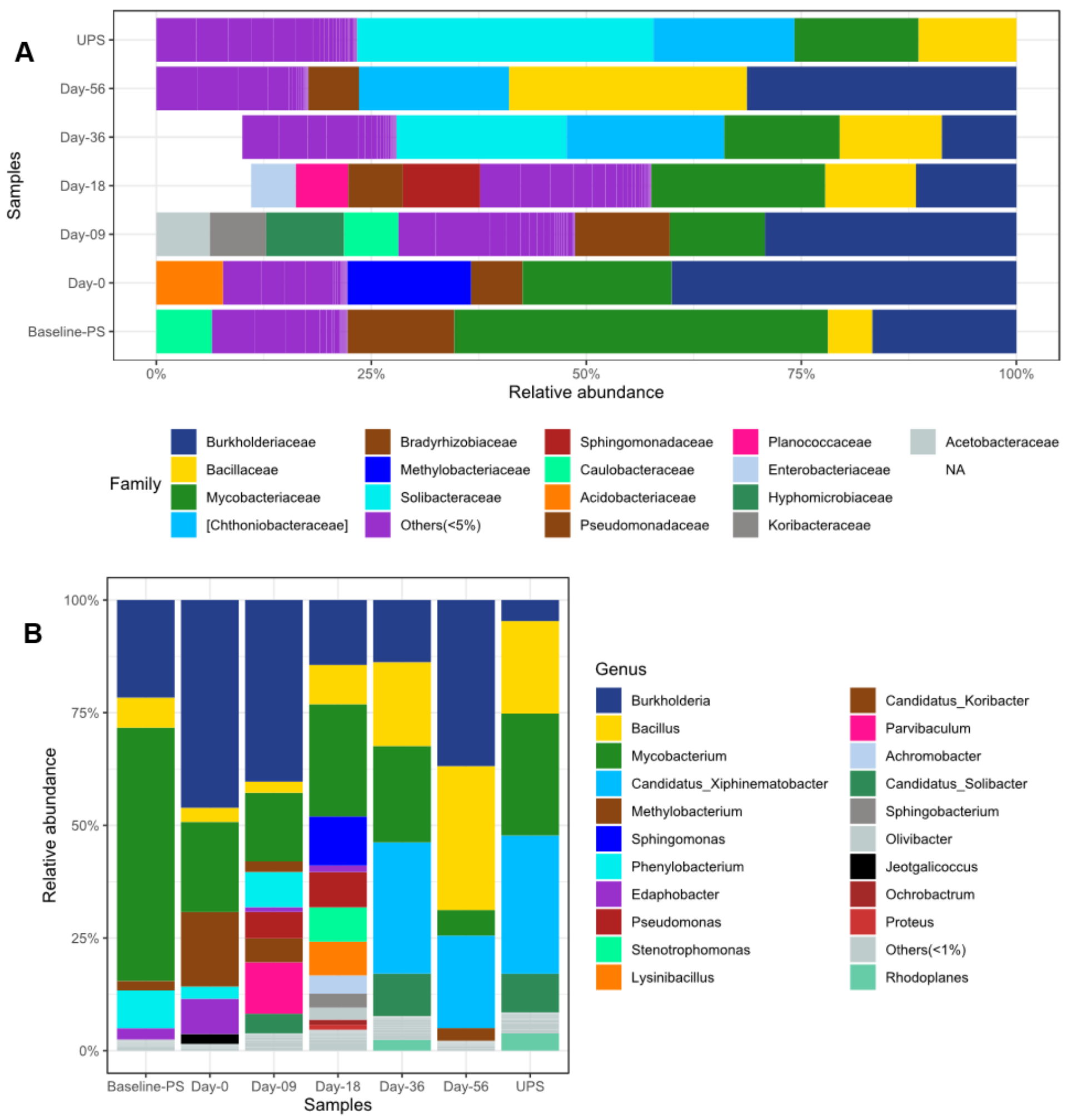

\section{Figure 4}

Distribution of bacteria at the family and class taxonomic levels as remediation of the oil-polluted site progressed. 

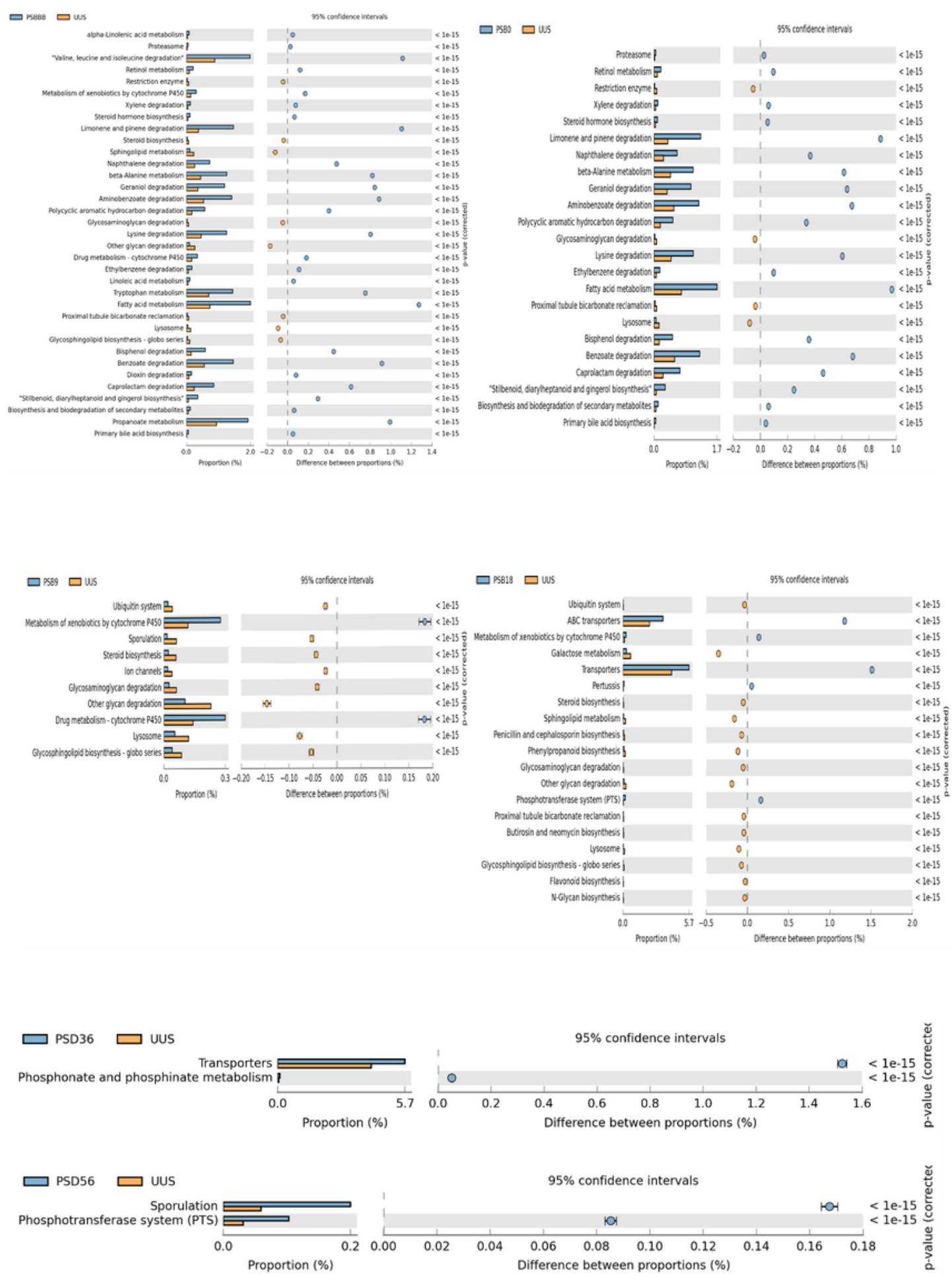

\section{Figure 5}

A. Significantly differential functional pathways among the pristine soil, the baseline soil prior to landfarming and the day 0 soil sample when remediation commenced. ${ }^{*}$ PSBBB $=$ Polluted soil prior to landfarming * PSBO $=$ Day 0 * UUS = Unpolluted soil B. Significantly differential functional pathways among the pristine soil, the day 09 and day 18 soil samples. ${ }^{*}$ PSB9 $=$ Day 09 * PSB18 = Day 18 C. 
Significantly differential functional pathways among the pristine soil, the day 36 soil and day 56 soil samples. * PSD56 $=$ Day 56 * PSD36 $=$ Day 36

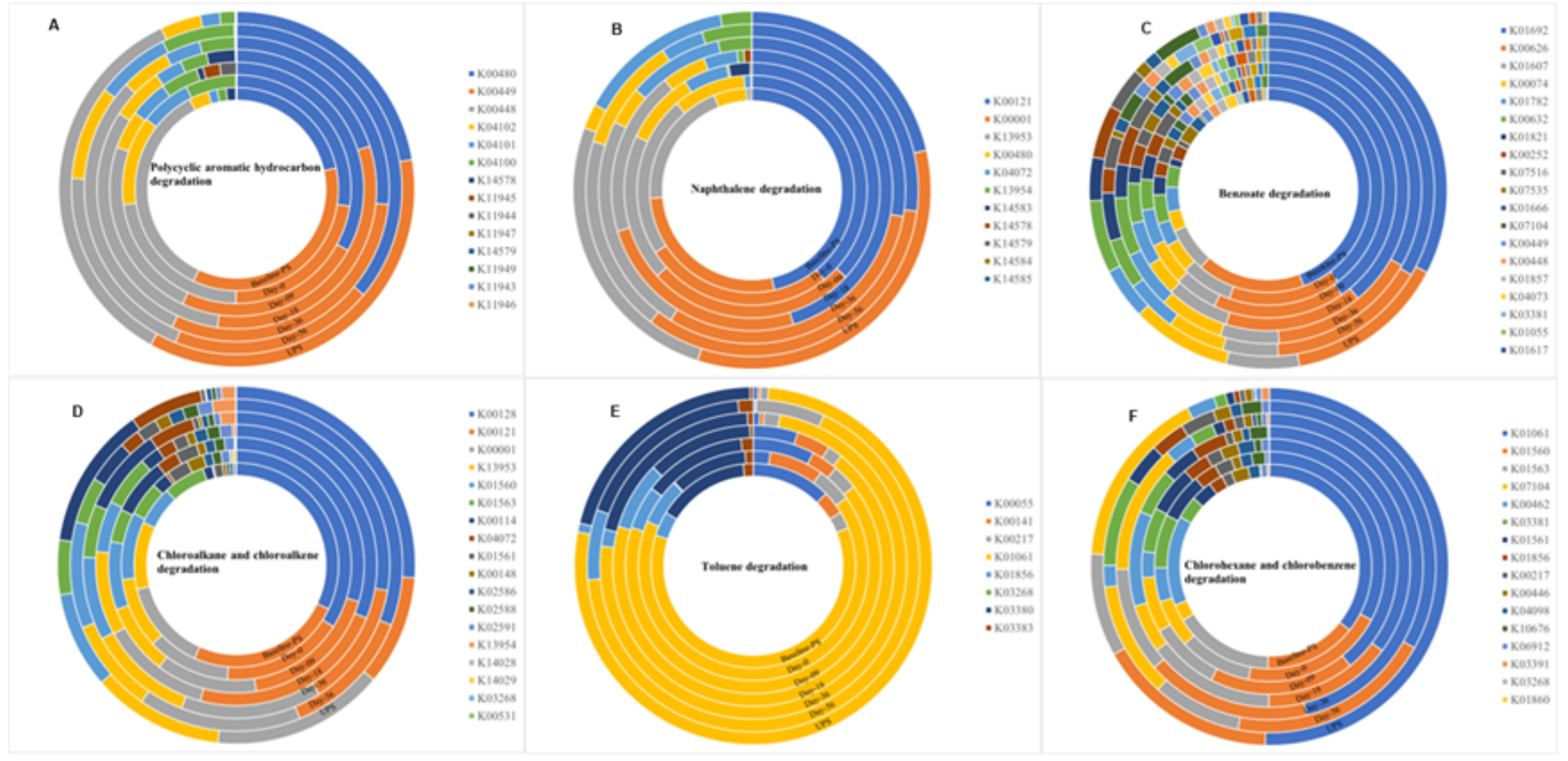

Figure 6

Distribution of enzymes associated with the degradation of polycyclic aromatic hydrocarbons and xenobiotics in the oil-polluted soil prior to and during remediation compared to the unpolluted soil. (A) Distribution of KEGG orthologs associated with PAHs degradation. (B) Distribution of genes responsible for Naphthalene degradation. (C) Distribution of KEGG orthologs associated with benzoate degradation. (D) Distribution of KEGG orthologs associated with chloroalkanes and chloroalkenes degradation. (E) Distribution of genes responsible for toluene degradation. (F) Distribution of KEGG orthologs responsible for Naphthalene degradation. 